\title{
Documentos/
}

\section{Proyecto de ley de los pueblos indígenas del Centro, Norte y Pacífico de Nicaragua}

\section{Presentación}

Constituye un hito histórico en la historia de Nicaragua el hecho que los pueblos indígenas del Pacifico, Centro y Norte puedan intervenir en el proceso de formación de una ley que regule su autonomía, y demás característica de entes públicos, con un régimen sui generis de propiedad. Este proceso es ahora posible debido a la Reforma de 1995 que en el párrafo 3 del Artículo 5 de la Constitución Política de Nicaragua establece: “....El Estado reconoce la existencia de los pueblos indigenas, que gozan de los derechos, deberes y garantías...de mantener y desarrollar su identidad y cultura, tener sus propias formas de organización social y administrar sus asuntos locales..." Este reconocimiento a los pueblos indígenas, efectuado por la Reforma, no hace la distinción entre los pueblos indígenas del Pacifico y los del Caribe de Nicaragua, que hizo inicialmente la Constitución Política de Nicaragua, emitida en 1987, al reconocer solamente a los pueblos indígenas y comunidades étnicas de la Costa Atlántica. Por lo que los pueblos Indígenas del Pacifico, Centro y Norte continuaron, entre 1987 y 1995, bajo el régimen de la legislación emitida por el Estado nicaragüense entre 1877 y 1952. Esta legislación que fue aplicada por más de un siglo tuvo como resultado el despojo de sus tierras comunales y la implosión de las municipalidades sobre las autoridades tradicionales comunales, tratadas como simples dueños de una comunidad de bienes, regulada por el Código Civil de Nicaragua. A pesar de que estas leyes actualmente son incompatibles con lo establecido por la reforma constitucional de 1995, como lo ha señalado en reiterada jurisprudencia la Corte Suprema de Justicia al pronunciarse sobre su inaplicabilidad, específicamente por las autoridades municipales las cuales bajo el esquema anterior eran las encargadas de aplicarla. La Corte ha señalado específicamente el Arto. 177 in fine, de la Constitución, que establece que:..."La Ley de Municipios deberá incluir, entre otros aspectos, las competencias municipales, las relaciones con el gobierno central, con los pueblos indígenas de todo el país y con todos los poderes del Estado, y la coordinación interinstitucional”. Instituyendo de esta manera una nueva relación entre las comunidades indígenas y las municipalidades, en las cuales cada una conserva su autonomía, y a los pueblos indígenas se les garantiza el derecho de "tener sus propias formas de organización social y administrar sus asuntos locales" dejando atrás la sujeción a la municipalidad, que establecía la legislación existente entre 1877 a 1952. Sin embargo, la intervención de los Pueblos Indígenas del Pacifico, Centro y Norte de Nicaragua en este proceso de formación de una ley que los regule, de conformidad con las normas constitucionales vigentes, ha tenido ya una duración de aproximadamente cinco años desde que se entregó el primer anteproyecto de Ley a la Asamblea Nacional, sin que la Ley haya sido aprobada. Consecuentemente, los pueblos indígenas del Pacifico, Centro y Norte continúan siendo el único sector social nicaragüense que carece de una ley que efectivamente los proteja de la discriminación y del despojo de que han sido objeto desde hace mas de cinco siglos. Por lo que hoy los Pueblos Indígenas del Pacifico, Centro y Norte entregan a la actual Legislatura de la Honorable Asamblea Nacional el reto de procurar para estos pueblos una efectiva protección estatal sin discriminación. 
DECLARACION DE LOS PUEBLOS INDIGENAS

LIDERES Y ORGANIZACIONES INDIGENAS DEL

PACIFICO CENTRO Y NORTE DE NICARAGUA.

Reunidos lideres, lideresas, autoridades de Pueblos Indígenas y organizaciones indígenas del Pacifico Centro y Norte de nuestro país, los días 27, 28 y 29 de julio del año dos mil nueve en Pueblo Viejo, Managua, nos hemos puesto de acuerdo y en conjunto analizamos y consensuamos el proceso que ha seguido el Anteproyecto de Ley de Pueblos Indígenas del Pacifico Centro y Norte de Nicaragua

\section{Considerando:}

Que por mandato constitucional y en cumplimiento a los establecido en la Declaración Universal de las naciones Unidas sobre los derechos indígenas, el Convenio 169 de la OIT, la Convención Internacional Contra todas las formas de Discriminación Racial, Las Recomendaciones del Comité Contra la Discriminación Racial de Naciones Unidas y otras normas internacionales sobre derechos indígenas

Que por unanimidad los lideres, lideresas y representantes de organizaciones indígenas del pacifico centro y norte de Nicaragua, estamos conscientes de la necesidad de contar con una Ley de Pueblos Indígenas que reúna las condiciones y el espíritu necesario para nuestro etnodesarrollo,

Que el actual proceso de formación de la Ley de Pueblos Indígenas del Pacifico Centro y norte lleva ya alrededor de cinco años, y aún no se aprueba; y sentimos que injustificadamente nosotros estamos siendo discriminados ante la aprobación de leyes para otros sectores de la sociedad nicaragüense.

Que en Nicaragua todos los sectores sociales tienen sus propias leyes y los Pueblos Indígenas no contamos con un instrumento jurídico que reconozca nuestros derechos, ya que las leyes existentes con muchos vacíos legales, discriminatorios, obsoletas y elaboradas a conveniencia de los grupos de poder, tienen mas de cien años de existencia.

Que la paciencia de nuestros pueblos se ha agotado, hoy unidos en un solo bloque hemos decidido en una sola voz en defensa de nuestros derechos pronunciarnos por tanto,

\section{RESOLVEMOS.}

1. Exigir la inmediata aprobación de la Ley de Pueblos Indígenas del Pacifico Centro y Norte de Nicaragua, tal y como la presentamos a la fecha. De conformidad con el artículo 19 de la
Declaración de las Naciones Unidas sobre los Derechos de los Pueblos Indígena y la Ley de Participación Ciudadana.

2. Exigir la Ratificación del Convenio 169 de la OIT.

3. No aceptar la propuesta de la Comisión de Asuntos Étnicos de conformar una Comisión Interinstitucional para la Resolución de los Conflictos de los Pueblos Indígenas. Ya que es el Sistema Judicial el que tiene que dirimir estos asuntos de conformidad con la Constitución Política de Nicaragua.

4. Realizar el proceso de Consulta y Consenso del anteproyecto de Ley de Medicina Tradicional con las autoridades, líderes y terapeutas de los pueblos indígenas en el tiempo que sea necesario.

5. Exigir el respeto del estado de Nicaragua a la libre autodeterminación de los pueblos indígenas en la resolución de sus asuntos internos.

6. Ratificar nuestra firme unidad como Pueblos, Lideres, lideresas y Organizaciones Indígenas del Pacifico Centro y Norte de Nicaragua, asumiendo y firmando la presente Declaración, que será divulgada por todos los medios de comunicación posibles y dada a conocer a todas las instituciones y organismos nacionales e internacionales.

Dado en Pueblo Viejo de la ciudad de Managua, a los veintinueve días del mes de julio del año dos mil nueve.

Coordinadora Chorotega

Coordinadora Diriangen

Coordinadora Nicarao

Coordinadora Adiact Agateite

Coordinadora Dirian Tenderi

Movimiento Indígena de Nicaragua

Monexicos

Red de Pueblos Indígenas

Movimiento Indígena de Jinotega

\section{Proyecto de Ley de los Pueblos Indígenas del Pacífico, Centro y Norte de Nicaragua}

\section{Ley No.}

\section{CAPITULO I}

\section{PRINCIPIOS GENERALES Y DEFINICIONES}

Arto. 1 El objetivo de la presente Ley es regular el derecho a la autodeterminación y la autonomía de los Pueblos y Comunidades Indígenas del 
Pacífico, Centro y Norte de Nicaragua, de raíces Chorotega, Cacaopera, Nahoa y Xiou; reiterar su personalidad y capacidad jurídica como entidades de derecho público, con un régimen de propiedad sui generis; así como sus formas de gobierno, jurisdicción y competencia, sujetas a la Constitución Política de Nicaragua.

Arto. 2 Son objetivos específicos de la presente Ley:

a) Desarrollar las disposiciones y principios constitucionales referente a los Pueblos y Comunidades Indígenas de Nicaragua contenidas en los artículos 4, 5, 8, 25, 27, 46, 49, 50, 103, 107, 126, 128, y 179 de la Constitución Política de Nicaragua, y especialmente, los derechos de mantener y desarrollar su identidad y diversidad cultural, administrar sus asuntos locales, mantener sus propias formas de organización social, mantener las formas comunales de propiedad de sus tierras; así como garantizarles su efectivo uso, goce y disfrute.

b) Fortalecer el Estado Social de Derecho, la autodeterminación de los pueblos, la democracia, el pluralismo étnico, la multiculturalidad y el potencial de Desarrollo Humano de los Pueblos y Comunidades Indígenas, como Principios Fundamentales del Estado nicaragüense.

c) Regular la naturaleza jurídica de los Pueblos y Comunidades Indígenas, su jurisdicción, competencia; $\mathrm{y}$ la coordinación y complementariedad de los Gobiernos de los Pueblos y Comunidades Indígenas con el conjunto de la administración pública del Estado de Nicaragua.

d) Adecuar la legislación nicaragüense a las disposiciones contenidas en la Declaración de las Naciones Unidas sobre los Derechos de los Pueblos Indígenas, suscrita por el Estado de Nicaragua el 7 de septiembre del 2007, y de la Convención Internacional sobre la Eliminación de Todas las Formas de Discriminación Racial, ratificada por el Estado de Nicaragua, mediante Resolución
Número 63 adoptada por el Congreso de la República el 21 de Octubre de 1977, de conformidad con la cual se deben eliminar las formas de discriminación y los obstáculos que aun persistan para la plena participación de los Pueblos y Comunidades Indígenas del Pacifico, Centro y Norte de Nicaragua en la vida política, económica, social y cultural de la nación.

Arto. 3 El Estado reconoce la existencia de los Pueblos y Comunidades Indígenas del Pacífico, Centro y Norte de Nicaragua, de conformidad con los principios de la nación nicaragüense, consignados en la Constitución Política, Arto. 5 párrafo 3, y por ende les reafirma su personalidad jurídica; la que ratifica sin más trámite por virtud de la presente ley.

Arto. 4 Los Pueblos Indígenas del Pacífico, Centro y Norte de Nicaragua, son parte integral de la nación nicaragüense, y gozan de los derechos colectivos propios de su cultura, tierra y autogobierno; así como sus miembros tienen igualdad de derechos, deberes y las garantías, como ciudadanos nicaragüenses, de acuerdo a lo consignado en la Constitución Política.

Arto. 5 Para efectos de la presente Ley se definen los siguientes conceptos:

Asamblea General Indígena: Es la máxima autoridad de cada Pueblo o Comunidad Indígena; conformada por las diferentes expresiones de autoridad del Gobierno Indígena, como son sus Órganos Normativos: Consejos de Ancianos y Monéxicos; los Órganos Ejecutivos: Juntas Directivas, y los Órganos Consultivos: asambleas de miembros de la comunidad o pueblo; así como otras formas de organización moderna, como las Comisiones de Trabajo, Promotores, Consejos de Jóvenes, Consejos de Mujeres. Todas estas expresiones de autoridad tendrán reguladas sus funciones en los Estatutos de cada Pueblo o Comunidad Indígena.

Autonomía de los Pueblos Indígenas: Es la potestad de los Pueblos y Comunidad Indígenas a desarrollar sus propias formas de organización social, administrar sus asuntos internos y mantener las formas comunales 
de propiedad de sus tierras, de acuerdo a sus usos, costumbres y tradiciones, preservando su identidad y cultura.

Autoridades Indígenas: Es toda Autoridad de los Pueblos o Comunidad Indígenas, objeto de ésta ley, elegida conforme a sus estatutos, usos, costumbres y tradiciones, para que los apoye, represente y gobierne, tales como: las Juntas Directivas, Consejos de Ancianos, Alcalde de Varas, Monéxicos, Caciques, Regidores, Reformas y cualquier otra denominación reconocidas por cada Pueblo o Comunidad Indígena.

Gobierno Indígena: Es la expresión política y administrativa, de conformidad con su jurisdicción y competencias, que adopta en forma autónoma las decisiones necesarias para la conducción de sus asuntos públicos internos y la administración del patrimonio indígena, de conformidad a sus usos, costumbres, tradiciones, estatutos y la presente Ley.

Pueblo Indígena: Es la colectividad humana que mantiene una continuidad histórica con las sociedades anteriores a la Colonia, cuyas condiciones sociales, culturales y económicas les distingue de otros sectores de la sociedad nacional y que están regidos total o parcialmente por sus propias costumbres y tradiciones.

Patrimonio Indígena: Es el conjunto de bienes tangibles e intangibles, materiales e inmateriales, que los Pueblos y Comunidades Indígenas han heredado de sus ancestros; incluyendo sus tierras comunales, los sistemas jurídicos, y todos los otros conocimientos tradicionales de naturaleza colectiva propios de su cultura; sean genéticos, medicinales, orales o escritos; así como cualquier otra manifestación cultural, artística, espiritual o sagrada, de la que se pueden derivar o reflejar en derechos o acciones.

Posesión Indígena: Es la presencia sobre un territorio por parte de un Pueblo o Comunidad Indígena, de acuerdo a sus usos, y costumbres, con ánimo de ejercer sus derechos patrimoniales. La posesión indistintamente puede ejercerse mediante la conservación de bosques u otros recursos naturales, por la realización de la actividad de: cacería, rituales religiosos o espirituales, sitios ceremoniales, presencia de vestigios arqueológicos, recreación, $\mathrm{u}$ otras expresiones culturales.

Propiedad Comunal o Comunitaria: Es la forma de propiedad, de naturaleza colectiva perteneciente a los Pueblos y Comunidades Indígenas, constituida por las tierras o territorios, aguas, bosques, fauna y otros recursos naturales del suelo y subsuelo, contenida en títulos reales, de remedidas, de compra venta; o que han pertenecidos tradicionalmente a los mismos pueblos o comunidades; o sobre los que estos han mantenido la posesión de acuerdo a sus usos, costumbres y tradiciones; y que actualmente puede encontrarse en uso individual o colectivo.

Titulo Real: Son los títulos de propiedad pertenecientes a los Pueblos Indígenas del Pacífico, Centro y Norte de Nicaragua; adquiridos durante la época colonial española, que acreditan el dominio y posesión sobre la tierra comunal indígena.

Títulos de Remedida: Son aquellos títulos tramitados y obtenidos por los Pueblos Indígenas del Pacífico, Centro y Norte de Nicaragua, ante la República Independiente de Nicaragua. Los cuales acreditan el dominio y posesión sobre la tierra comunal indígena.

\section{CAPITULO II}

\section{DE LA POLÍTICA SOCIAL DEL ESTADO HACIA LOS PUEBLOS INDIGENAS}

Arto. 6 Son elementos esenciales y ejes transversales de las Políticas Públicas del Estado nicaragüense hacia los Pueblos Indígenas, la multiculturalidad, la plurietnicidad, el pluralismo jurídico, el respeto a la propiedad comunitaria, y el desarrollo sostenible.

Arto. 7 El Estado deberá consultar con los Pueblos 
y Comunidades Indígenas todos los ante proyectos de ley, políticas publicas, proyectos, planes y programas que pretenda implementar, y que puedan tener impacto sobre sus miembros, tierras y medio ambiente, y demás asuntos del intereses de estos Pueblos y Comunidades.

Arto. 8 El Estado a través de sus instituciones, deberá articular en coordinación con las Autoridades Indígenas, un Programa de Atención a los Pueblos Indígenas, garantizando la seguridad alimentaria y el auto abastecimiento en la economía comunitaria, así como el desarrollo progresivo de la producción, dentro de la concepción de desarrollo sustentable.

Arto. 9 Las Instituciones del Estado encargadas de regular y controlar los recursos naturales, el medioambiente, la producción agropecuaria y forestal, los préstamos agrícolas y la propiedad urbana y rural, deberán respetar, garantizar y fomentar los usos y costumbres en la regulación de la propiedad comunitaria indígena.

Arto.10 Las instituciones del Estado que tengan bajo su control, documentación e información referida a la cultura, identidad e historia especifica de Pueblos y Comunidades Indígenas de Nicaragua, deberán facilitar informaciones y copias a las Autoridades Indígenas.

En los casos en que los documentos se encuentren deteriorados se buscará la restauración de los mismos para poder hacer uso de la información.

Arto. 11 A fin de insertar al país en el concierto internacional de naciones y en el ordenamiento jurídico internacional a favor de los derecho humanos; el Poder Ejecutivo a partir de la vigencia de la presente ley, debe someter para su aprobación, los Convenios y Tratados Internacionales suscritos por Nicaragua y relacionados con Pueblos Indígenas. De igual forma deberá suscribir aquellos instrumentos internacionales que se orienten al reconocimiento de estos derechos y a la eliminación de la discriminación racial.

\section{CAPITULO III}

\section{DEL PATRIMONIO ARQUEOLÓGICO Y CULTURAL DE LOS PUEBLOS INDIGENAS}

Arto. 12 Se reconoce el derecho de propiedad de los pueblos indígenas sobre los sitios sagrados ceremoniales, espirituales, de interés cultural, medicinatradicionaly los objetos arqueológicos, piezas de arte de cualquier naturaleza elaborada por los antecesores de los Pueblos Indígenas, los cuales no podrán ser administrados por el Estado sin el consentimiento de los Pueblos o Comunidades Indígenas.

La administración de los bienes que formen parte del patrimonio cultural de los Pueblos Indígenas y que se encuentren en poder de las instituciones del Estado, se deberá establecer acuerdo con el Gobierno Indígena que corresponda.

A partir de la vigencia de la presente Ley, toda pieza arqueológica u objeto de valor cultural que se descubra o encuentre, deberá ser reportada inmediatamente a la Autoridad Indígena, y la misma no podrá salir del Pueblo o Comunidad Indígena sin autorización, y previo dictamen de un experto en la materia.

Arto. 13 Los bienes que según la definición del artículo anterior forman parte del patrimonio indígena y se encuentren en poder de personas naturales o jurídicas, a cualquier título, serán restituidas a la Autoridad Indígena por mutuo acuerdo. Se exceptúan de esta disposición los bienes que se encuentran bajo la administración de la Dirección de Patrimonio Cultural de la Nación.

Arto. 14 Los Gobiernos Indígenas velarán por la posesión, conservación y protección, del patrimonio arqueológico e inmaterial existente en sus tierras y territorios tradicionales de conformidad con sus costumbres y tradiciones.

Arto. 15 El Estado deberá apoyar a los Pueblos y Comunidades Indígenas en la aplicación de 
medidas eficaces, para impedir la apropiación indebida de sus expresiones culturales, artísticas folclóricas y sus derivados; apoyar el control de la forma en que se utilizan fuera del contexto consuetudinario y tradicional; y promover la participación equitativa en los beneficios derivados de su utilización.

Arto. 16 El Estado respetará, garantizará, y preservará los conocimientos, tradicionales, las innovaciones y las prácticas de las Comunidades Indígenas que entrañen estilos tradicionales de vida pertinentes para la conservación y la utilización sostenible de la diversidad biológica y promoverá su aplicación más amplia con la aprobación y la participación de las Comunidades Indígenas que posean esos conocimientos, innovaciones y prácticas.

\section{CAPITULO IV}

\section{DE LA POLÍTICA SOCIAL DEL ESTADO HACIA LOS PUEBLOS INDIGENAS}

Arto. 17 Los Pueblos y Comunidades Indígenas tienen derecho a determinar su propio sistema de salud y educación, como base de la existencia cultural de estos pueblos y de su desarrollo sostenible.

Arto. 18 Las políticas públicas de salud incluirán y desarrollaran en el sistema de salud los principios de equidad e interculturalidad, así mismo, incorporarán la medicina tradicional de acuerdo a la cosmovisión y espiritualidad de los Pueblos y Comunidades Indígenas.

Arto. 19 El Ministerio de Salud a través de las instituciones que atienden a los territorios indígenas, garantizará, respetará, y promoverá los modelos de salud intercultural de estos Pueblos y Comunidades.

Arto. 20 Todo tipo de investigación que se realice en los territorios o con los Pueblos y Comunidades Indígenas deberá contar con la previa aprobación de las Autoridades Indígenas; la propiedad intelectual indígena en estos estudios deberá ser reconocida y una copia de los resultados de la investigación entregada al archivo del Pueblo o
Comunidad Indígena que participó.

Arto. 21 El Ministerio de Educación, Cultura y Deporte promoverá una educación intercultural, incorporando en sus planes y programas nacionales: el respeto de los valores y tradiciones indígenas, de acuerdo a la realidad que representa la diversidad étnica, cultural y lingüística que aportan a la nación los Pueblos y Comunidades Indígenas de Nicaragua.

Arto. 22 Las universidades del país que reciben fondos del Presupuesto General de la República, priorizarán dentro de sus programas de becas, y en coordinadamente con las Autoridades Indígenas, el otorgamiento de estas a estudiantes provenientes de Pueblos y Comunidades Indígenas.

Arto. 23 Los medios de comunicación: escritos, radiales, televisivos, de internet, etc., deberán promover en su programación y publicaciones la difusión de información pertinente, referida a la cultura, arte, historia y actualidad de los Pueblos y Comunidades Indígenas; como parte esencial de la diversidad cultural de la identidad del pueblo nicaragüense.

\section{CAPITULO V}

\section{DE LOS GOBIERNOS DE LOS PUEBLOS Y COMUNIDADES INDIGENAS}

Arto. 24 Son elementos constitutivos de los pueblos indígenas: La población, el gobierno, y el patrimonio indígena. La población enmarcada dentro la su jurisdicción indígena y perteneciente al pueblo indígena; su patrimonio, compuesto por los territorios y tierras comunales tradicionales, y demás bienes; su gobierno, autónomo e integrado por los órganos normativos, ejecutivos y consultivos, definidos de acuerdo a sus Estatutos.

Arto. 25 Los Pueblos y Comunidades Indígenas tienen en virtud de la Constitución Política de Nicaragua, Articulo 5, párrafo 3, existencia legal, para acreditar su personalidad jurídica deberán solicitar la publicación de sus Estatutos en la 
Gaceta, Diario Oficial; la que de manera gratuita, deberá realizar la publicación, en un término no mayor de un mes.

Arto. 26 La presente Ley reconoce las formas de gobierno existentes en cada uno de los Pueblos y Comunidades Indígenas del Pacifico, Centro y Norte de Nicaragua. Cuya naturaleza, elección, funciones, período, certificación, y ejercicio, se determina de conformidad con según sus usos, costumbres y tradiciones, los Estatutos y Reglamentos Internos de cada Pueblo o Comunidad Indígena, así como lo establecido en la presente Ley.

Arto. 27 La representación legal de las Autoridades Indígenas de cada pueblo, se acreditará con la certificación de la elección, emitida por el Directorio Electoral Indígena (DEI), realizadas de conformidad con los Estatutos de cada Pueblo o Comunidad Indígena.

Arto. 28 Los Estatutos de los Pueblos o Comunidades Indígenas del Pacifico, Centro y Norte de Nicaragua serán aprobados por la Asamblea General Indígena y deberán contener al menos lo relativo a:

a) Naturaleza, denominación, objetivos y domicilio del Pueblo o Comunidades Indígena;

b) Derechos y deberes de los miembros del Pueblo o Comunidad Indígenas;

c) Denominación, composición, periodo y funciones de los órganos del Gobierno Indígena;

d) Derechos y fomento de la participación de la mujer indígena en los órganos de autoridad, y en la toma de decisiones;

e) Causales de destitución de las autoridades del Gobierno Indígena;

f) Todo lo relacionado a las regulaciones de la administración del patrimonio del Pueblo o Comunidad Indígena;

g) Todo lo relacionado con las finanzas y las formas de auditar o controlar la contabilidad que llevan las autoridades del Gobierno Indígena;

h) El plan de recaudación de cánones y erogaciones de todo tipo;

i) Todo lo relacionado a la convocatoria y realización de Asambleas Generales Indígenas y Extraordinarias;

j) La creación del Directorio Electoral Indígena (DEI) y el procedimiento electoral de autoridades;

k) Cualquier otro asunto de interés general para el Pueblo o Comunidad Indígena.

Cada Pueblo o Comunidad Indígena a la entrada en vigencia de la presente ley, deberá elaborar o reformar sus estatutos de acuerdo con la misma y según sus costumbres y tradiciones; una vez elaborados los estatutos o sus reformas, la Autoridad Indígena que determinen sus estatutos, los mandará a publicar sin ningún otro trámite, en La Gaceta Diario Oficial; la publicación en la Gaceta se hará de forma gratuita.

Arto. 29 Los Gobiernos Indígenas integrarán sus órganos de autoridad en base a la democracia comunitaria, por la cual hombres y mujeres tendrán igual derecho a ser elegidos; con la sola condición de ostentar el estado legal de ascendencia indígena, determinado según los Estatutos de cada Pueblo o Comunidad Indígena.

Arto. 30 En las elecciones de autoridades de los Gobiernos Indígenas participan los ciudadanos indígenas mayores de 16 años de la jurisdicción, inscritos en el padrón electoral indígena, censo poblacional aprobado por la Asamblea General Indígena.

Arto. 31 Las Elecciones de todas Autoridades Indígenas estarán dirigidas por el Directorio Electoral Indígena (DEI) que será electo por la Asamblea General Indígena para un período de cuatro años, y de conformidad con los Estatutos de cada Pueblo o Comunidad Indígena.

En la elección de Autoridades Indígenas, invitados por el DEI, podrá participar un delegado del Consejo Electoral Departamental o uno de los Gobiernos Municipales de la jurisdicción de la Comunidad o del Territorio Indígena, los que acudirán como observadores.

Arto. 32 El Directorio Electoral Indígena (DEI) estará compuesto por un Presidente, un 
Vicepresidente, un Secretario, un Responsable de Logística y un Vocal.

Las funciones particulares de cada miembro serán definidas por el reglamento interno, que deberán elaborar a más tardar un mes después de ser constituidos.

Arto. 33 Son funciones del Directorio Electoral Indígena (DEI), las siguientes:

a) Elaborar su plan de trabajo y el presupuesto para asegurar el proceso electoral, distribuyendo responsabilidades entre sus miembros.

b) Revisar el censo y elaborar el padrón electoral con los integrantes de la comunidad o pueblo indígena censados que según el registro hayan cumplido 16 años.

c) Publicar el Padrón Electoral en los locales designados como Centros de Votación.

d) Informar a los integrantes del Padrón Electoral, el local donde le corresponderá ejercer la votación.

e) Emitir los Carné de Identidad a las personas registradas en el censo que hayan cumplido los 16 años de edad para que puedan identificarse al momento de la votación

f) Convocar oficialmente a las elecciones con noventa días de anticipación.

g) Integrar y capacitar al personal técnico que trabajará en los procesos electorales conformando un listado con el cual pueda contar para la realización de cada elección.

h) Asegurar todos los recursos materiales y logísticos para el desarrollo de las elecciones el día de la votación.

i) Elaborar y resguardar las boletas electorales y codificarlas el día de la votación, con un número acordado entre los integrantes de la Junta Receptora y los fiscales de las ternas contendientes.

j) Elaborar el Escrutinio de los resultados electorales y resolver las impugnaciones presentadas, así como certificar los resultados una vez resueltas las impugnaciones y recursos.

k) Resolver las impugnaciones que deben presentarse en un plazo máximo de tres días después de la elección y deberán ser resueltas a más tardar en un término de cinco días. Y los recursos de revisión que se presentarán a mas tardar tres días después de notificado el resultado de las impugnaciones, y deben ser resueltas en un periodo máximo de cinco días.

1) Elaborar un informe final en el que hará constar los resultados de cada Junta Receptora, los recursos presentados y su resolución así como los resultados finales.

m) Elaborar el Acta de Resultados Electorales donde refleje la cantidad de votos obtenidos y proclamar a la autoridad electa.

n) Emitir la certificación de las autoridades electas.

Arto. 34 Los procesos de elección celebrados en contravención a lo dispuesto en los artículos que anteceden, serán objetos de nulidad absoluta. Esta, será declarada por medio del Directorio Electoral Indígena (DEI) electo por la Asamblea General Indígena, el cual se regirá por su Estatuto y Reglamento Interno correspondiente.

Arto. 35 Una vez realizadas las elecciones, el órgano saliente hará entrega a las nuevas autoridades electas, ante las Autoridades Tradicionales de cada pueblo, de su cargo, libros, documentos, títulos, bienes e informe económico previamente auditoriados. Dicha entrega se realizará en un plazo no mayor de un mes, contado a partir de la fecha de la elección de las nuevas autoridades.

Arto. 36 En caso de inobservancia a lo dispuesto en el articulo anterior, las nuevas autoridades acudirán a las autoridades judiciales correspondientes a presentar su denuncia o demanda, en contra de las autoridades salientes, quien las requerirá para que en un plazo de tres días entreguen los bienes y sus inventarios; sino entregan el cargo, los bienes y documentos bajo su administración, el juez que conoce del asunto les decretará apremio corporal el que podrá suspenderse hasta la entrega del cargo en la forma establecida en el artículo anterior. 


\section{CAPITULO VI}

\section{DE LAS ASAMBLEAS INDIGENAS}

Arto. 37 Los Gobiernos Indígenas realizarán una Asamblea General Indígena abierta cada año, para tratar el Plan de Recaudación, el presupuesto, el informe de gestión y el Plan Anual de Desarrollo del Pueblo o Comunidad Indígena. Estas asambleas son de carácter obligatorio y se convocarán con treinta días de anticipación. La Asamblea Indígena se realizará en las fechas establecidas en el Estatuto o Reglamentos Internos de cada Pueblo o Comunidad Indígena.

Arto. 38 En forma extraordinaria, el Gobierno Indígena podrá convocar a asamblea con un mes de anticipación, cuando sea decisión de la mayoría simple de los Consejos de Ancianos o de las Juntas Directivas del Gobierno Indígena.

Arto. 39 También procederá a celebrarse asambleas extraordinarias, cuando lo pidan los miembros de los Pueblos o Comunidades Indígena, de acuerdo a sus Estatutos.

Arto. 40 El Secretario del Gobierno Indígena abrirá un libro que contendrá las actas de cada asamblea realizada.

\section{CAPITULO VII}

\section{DE LA JURISDICCION INDÍGENA Y RESOLUCIÓN DE CONTROVERSIAS EN TERRITORIO INDÍGENA}

Arto. 41 El Poder Judicial debe respetar, garantizar y fortalecer las instituciones de derecho consuetudinario de los Pueblos y Comunidades Indígenas del Pacifico, Centro y Norte de Nicaragua, mediante la creación de regulaciones especiales en coordinación con las Autoridades Indígenas; y procurando la coherencia y la coordinación en las actuaciones de los jueces del Sistema Judicial nacional y las Autoridades Indígenas, de conformidad con lo establecido en el Arto. 5 numeral 3 de la Constitución Política de Nicaragua.
Arto. 42 Las autoridades indígenas podrán emitir normativas y resoluciones para regular el uso de la tierra, las elecciones de autoridades, la elaboración del censo, la protección de sus recursos naturales, el presupuesto, la construcción de caminos internos dentro del territorio indígena y demás asuntos que correspondan con sus legítimos intereses; estas normativas y resoluciones deberán ser acatadas por los indígenas y los usuarios de tierras indígenas.

Arto. 43 Toda desavenencia que surja entre los miembros del Pueblo o Comunidad Indígena y los no indígenas, dentro de la jurisdicción del Pueblo o Comunidad Indígena, relacionados a la tenencia de la tierra comunal, el uso administración de recursos naturales, a la incorporación en el censo comunal, a los conflictos intrafamiliares, la aplicación de los estatutos, y a cualquier otro asunto de interés general en el territorio indígena, será dirimido por la Autoridad Indígena.

Estos asuntos podrán ventilarse judicialmente hasta que se haya agotado la tramitación a lo interno del Pueblo o Comunidad por la Autoridad Indígena. La constancia de la Autoridad Indígena de haber tratado el asunto y su resolución, será requisito para que el juez estatal admita el asunto en la jurisdicción ordinaria.

Los asuntos tratados y las soluciones aceptadas por las partes, causarán estado, y no podrán ser ventilados ya ante la jurisdicción ordinaria, por lo cual la constancia y resolución de la Autoridad Indígena podrá ser opuesto como excepción ante el juez estatal.

Arto. 44 La Policía Nacional deberá prestar auxilio a la Autoridad Indígena para el cumplimiento de sus resoluciones y el ejercicio de sus atribuciones.

Arto. 45 Los asuntos de familia dentro del Pueblo o Comunidad Indígena se dirimirán ante la Autoridad Indígena; solamente cuando se haya agotado esta instancia, se podrá acudir a la jurisdicción ordinaria.

Arto. 46 La familia en los Pueblos o Comunidades Indígenas, la constituyen sus miembros, 
identificados como indígenas por sí mismos y reconocidos por la Autoridad Indígena. Los Gobiernos Indígenas, garantizan y promueven la protección principalmente a la mujer y a los menores contra toda violencia intra-familiar y sexual, en sus jurisdicciones.

Arto. 47 El Gobierno Indígena garantizará, los derechos y el desarrollo integral de la mujer indígena, así como su participación en toda la esfera de la vida comunitaria, para que continúe desempeñando su papel como transmisora de valores culturales y conocimientos tradicionales; como consejera, lideresa, o guía espiritual.

Arto. 48 En los procesos de adopción de niños o niñas indígenas, las entidades estatales darán prioridad a las personas o persona indígena que soliciten la adopción.

En caso que la entidad estatal pretenda separar a un niño, niña o adolescente de su padre o madre residente en la comunidad indígena, la entidad administrativa o judicial deberá consultar con la Autoridad Indígena, y la opinión de esta será vinculante.

Arto. 49 En caso de detención policial de uno de los miembros del Pueblo o Comunidad Indígena, las autoridades policiales deberán dar aviso a la Autoridad Indígena de la jurisdicción del Pueblo o Comunidad a la que pertenece el detenido.

\section{CAPITULO VIII}

\section{DEL REGIMEN DE PROPIEDAD COMUNITARIA}

Arto. 50 Las tierras comunales de los Pueblos y Comunidades Indígenas del Pacífico, Centro y Norte son aquellas que les han pertenecido de manera colectiva, en virtud de un titulo, o las que han mantenido de manera tradicional en posesión, de acuerdo a sus usos y costumbres; las tierras indígenas son inalienables, inembargables e imprescriptibles.

Arto. 51 Los Títulos Reales otorgados por el Rey de España al común del Pueblo Indígena, los Títulos de deslinde y amojonamiento aprobados por el Gobierno Republicano, así como los títulos adquiridos por asignación compra venta al Estado o a particulares por parte de los pobladores o miembros de las actuales Comunidades o Pueblos Indígenas, u otros Títulos obtenidos por cualquier mérito, a nombre colectivo o de sus representantes, constituyen Título de Dominio suficiente para acreditar el Derecho de Propiedad sobre dicho Patrimonio Indígena.

Arto. 52 El Estado bajo ninguna circunstancia otorgará Títulos Supletorios, Ventas Judiciales, Prescripción, Declaración de Mejoras, Títulos de Reforma Agraria, o cualquier otra forma de súper posición de Títulos en tierras Indígenas Tituladas o territorios tradicionalmente utilizados por los Pueblos y Comunidades Indígenas del Pacífico, Centro y Norte, de Nicaragua.

Arto. 53 Las autoridades judiciales de la República al tramitar una acción de Venta Judicial, Título Supletorio, Declaración de Prescripción, Reivindicación, y de cualquier otro forma que amenace el patrimonio de un Pueblo o Comunidad Indígena del Pacífico, Centro y Norte, de Nicaragua; deberán de oficio, mandar a oír a las autoridades del Gobierno Indígena de su jurisdicción, a fin de que aleguen el derecho que les asiste, so pena de nulidad del trámite. La carga de prueba de estos casos estará a cargo de del demandante, quién deberá demostrar que la propiedad no pertenece al Pueblo o Comunidad Indígena, al tenor del Arto. 782 del Código de Procedimiento Civil.

Arto. 54 Para efectos del efectivo ejercicio legal del derecho de propiedad comunitaria, los títulos de propiedad otorgados a favor del Común de Indios, de la Comunidad Indígena, de los pobladores de la comunidad, de los habitantes del poblado y otras denominaciones utilizadas en los títulos antiguos, deben entenderse otorgados a favor de la nueva razón social denominada Pueblo o Comunidad Indígena, la cual le sustituye sin solución de continuidad.

Arto. 55 De conformidad con lo establecido por la Ley 452, Ley de Solvencia Municipal y Ley 453, Ley de Equidad Fiscal, los Pueblos Indígenas 
están exentos del pago de Impuestos de Bienes Inmuebles (IBI) y de Impuestos sobre la Renta (IR) exenciones que reitera la presente ley.

\section{CAPITULO IX}

\section{DEL REGISTRO DE LA PROPIEDAD DE LOS}

PUEBLOS INDIGENAS

Arto. 56 Los Registradores de la Propiedad, deberán inscribir en un libro especial que se abrirá para llevar el registro de la propiedad comunitaria, todos los contratos de arriendo y usufructo otorgado por la Autoridad Indígena.

Arto. 57 Los Registradores de la Propiedad que tengan conocimiento de Sentencia Judicial, de cualquier índole, Título de Reforma Agraria, Supletorio, o de cualquier tipo, presentado para su inscripción, que no provenga de la Autoridad Indígena competente, y que se encuentre dentro de la propiedad de algún Pueblo o Comunidad Indígena, deberán abstenerse de inscribirlo, razonando el instrumento presentado con la explicación pertinente, de conformidad con lo establecido por la presente Ley.

En caso de que el título regresado proceda de Resolución Judicial, la autoridad judicial, antes de pronunciarse sobre la negativa del Registrador, deberá mandar a oír al Gobierno Indígena a fin de que pueda hacer uso de sus derechos.

Arto. 58 Cada Pueblo o Comunidad Indígena llevará un Libro de Registro Interno de la Propiedad Comunitaria Indígena, en el que se inscribirán todos los contratos que otorgue el Gobierno Indígena. Este libro tendrá al menos dos columnas, una de inscripciones y otra de anotaciones donde se llevará traspasos, pago de canon, gravámenes y libertad de gravámenes que existan sobre el derecho otorgado, así como cualquier otra situación que afecte la propiedad y que a juicio del Gobierno Indígena sea importante registrar.
Arto. 59 La Autoridad Indígena podrá llevar un Protocolo Indígena, para el otorgamiento de los contratos de arriendo o de usufructo, el que deberá contener las mismas formalidades que establece la Ley de Notariado, los testimonios librados deberán ser firmados por el Secretario del Pueblo o Comunidad Indígena y podrán inscribirse en el Registro de la Propiedad.

Arto. 60 Los Pueblos Indígenas que por virtud de algún decreto ejecutivo o alguna ley, fueron limitadas en el ejercicio de su derecho de propiedad, por ministerio de la presente Ley, se les reconoce plenamente el ejercicio de sus derechos, sin más limitaciones que las establecidas en la Constitución Política de Nicaragua.

Arto. 61 Cada Pueblo o Comunidad Indígena, deberá llevar un Catastro Indígena, consistente en un inventario, representación y descripción grafica, alfanumérica y estadística de todos los bienes inmuebles comprendidos dentro de su territorio, ordenados y codificados de acuerdo a su ubicación geográfica y sus usuarios. Este Catastro deberá ser respetado por el Instituto de Estudios Territoriales y el Ministerio de Hacienda y Crédito Público e incorporado dentro del sistema de Catastro Nacional.

\section{CAPITULO X}

\section{DE LA SEGURIDAD JURÍDICA EN LA TENENCIA DE LA PROPIEDAD INDÍGENA}

Arto. 62 El uso de las tierras indígenas y de los recursos naturales que en ellas se encuentren es un derecho exclusivo de los Pueblos y Comunidades Indígenas. Sus miembros tienen derecho a recibir del Gobierno Indígena contratos de usufructo de por vida, para el aprovechamiento de la tierra, los que podrán transmitir por herencia a sus sucesores, o ceder a otros indígenas de conformidad con sus Estatutos. Y los no indígenas podrán recibir contratos de arriendo acordados por un plazo que en ningún caso podrá exceder de diez años. 
Arto. 63 Toda aprobación de contratos sobre el uso y aprovechamiento, así como las operaciones relacionadas a éstos, de tierras y recursos naturales del patrimonio indígena, deberá decidirse de conformidad con los Estatutos y Reglamentos Internos de cada Pueblo o Comunidad Indígenas y por lo prescrito por la presente Ley.

Arto. 64 Son usuarios de tierras indígenas, personas naturales y jurídicas, que mediante contrato otorgado por la Autoridad Indígena, han adquirido tal derecho, sean estos miembros de la Comunidad Indígena o no. Los contratos podrán ser otorgado mediante Escritura Pública y donde no exista Notario Público, por medio de un Protocolo Indígena que llevará la Junta Directiva, y estará a cargo del Secretario, para lo cual se cumplirá las mismas formalidades establecidas en la Ley Notarial.

Arto. 65 Para el otorgamiento de los contratos de arriendo sobre el uso de la tierra indígena, y operaciones relacionadas a las mismas, deberá concurrir el voto favorable de cinco miembros de la Junta Directiva, cuya firma dará validez al documento en que conste dicho contrato; pudiéndose comisionar en el mismo a cualquier miembro de la Junta Directiva para que comparezca ante Notario para el otorgamiento de la Escritura Pública correspondiente, so pena de nulidad; la Escritura Pública deberá contener íntegramente las cláusulas del contrato de arriendo o del usufructo otorgado por la Junta Directiva.

Arto. 66 Los miembros del Pueblo o Comunidad Indígena, podrán probar, su derecho con la inscripción de su parcela en el Libro de Registro de la Comunidad Indígena según la Certificación emitida por Secretaria de la Junta Directiva, sin perjuicio del otorgamiento de escritura en el Protocolo del Pueblo o Comunidad Indígena.

Arto. 67 Todos los arrendatarios de tierras indígenas, deberán pagar el canon de arriendo establecido conforme al plan de recaudación aprobado por la Autoridad Indígena.

Arto. 62 Las mejoras que el usuario de las tierras indígenas realice con la autorización de la Autoridad Indígena, serán de su propiedad y en caso de rescisión anticipada del contrato por razones ajenas a su voluntad, deberán ser indemnizadas.

Arto. 68 Los derechos de uso de las tierras indígenas podrán ser hipotecados como garantías para obtener financiamiento productivo y de otra índole, previa autorización de la Autoridad Indígena, en la cuales se consigne el aval para la hipoteca y la garantía al acreedor de que en caso de mediar sentencia firme en su contra se haga efectivo el pago de su obligación, mediante la adjudicación al acreedor del derecho de uso y las mejoras contenidas.

En el caso establecido en el párrafo anterior, se exceptúa la vivienda familiar de los miembros del Pueblo o Comunidad Indígena.

Arto. 69 Cuando un arrendatario o usufructuario resultare demandado por alguien que cuestione la propiedad indígena o los derechos del usuario sobre ella, el demandado deberá ser apoyado por la Autoridad Indígena, la que invocará sus derechos sobre la propiedad.

Arto. 70 Los usuarios de tierras indígenas están en la obligación de proteger los recursos naturales, y podrán también emprender acciones de restauración de los mismos; por la inversión en la conservación y rescate de los recursos naturales, podrán ser exonerado en un porcentaje del pago del canon y tener asegurado la prorroga de su contrato al vencimiento del plazo establecido.

Arto. 71 Ningún usuario de tierras comunales podrá aprovechar sin permiso previo por escrito de la Junta Directiva, el bosque, su biodiversidad, agua, o ningún otro recurso natural en el suelo y el subsuelo del Pueblo o Comunidad Indígena.

Arto. 72 Ningún usuario de tierras indígenas podrá obstruir el paso a la Comunidad o Pueblo cuando este ha existido históricamente, o impedir abrirlo cuando sea necesario, quedando la opción de abrirlo a la Autoridad Indígena.

Arto. 73 Toda persona que ocupe tierras indígenas, sin ser miembro legítimo de la Comunidad o Pueblo, deberá solicitarlos en arriendo ante la Junta Directiva, y de obtener la aprobación de 
esta, procederá a la medida del lote o lotes de terreno que ocupe para determinar su extensión y así determinar el valor del canon.

Los que no cumplieren con la disposición establecida en el párrafo anterior, no tendrá derecho a permanecer, ni practicar o mantener encierro de ninguna clase en la tierra indígena, quedando a opción de la Junta Directiva demandar la restitución o exigir el valor del canon del tiempo que el terreno fue utilizado.

Para determinar el valor del canon, la Junta Directiva, previa inspección del terreno, fijará el número de hectáreas abarcadas por el ocupante, no pudiendo este eximirse del pago del precio entonces establecido; sino mediante medida, practicada por agrimensor titulado, aprobada por la Autoridad Indígena y además, del pago de los gastos consiguientes ocasionados.

Arto. 74 El Gobierno Indígena podrá demandar por la vía sumaria o especial en la jurisdicción ordinaria, la restitución de los terrenos, a los arrendatarios que no cancelen el correspondiente canon de arriendo, o incumplan las cláusulas de los contratos establecidos con la Autoridad Indígena.

Cuando el usuario abandone el área arrendada por más de seis meses, la Autoridad Indígena procederá a lo inmediato a intervenirla y nombrar un depositario para asegurar la protección y resguardo del bien.

Arto. 75 Los contratos de arriendo de las tierras indígenas, podrán ser rescindidos de común acuerdo entre las partes y unilateralmente solo de conformidad con las causales establecidas en el contrato respectivo, los Estatutos comunales y la presente Ley.

Arto. 76 Las cláusulas y estipulaciones contenidas en los contratos de uso de las tierras indígenas en contravención de la presente Ley se considerarán sin valor alguno.

Arto. 77 La Autoridad Indígena será responsables institucionalmente por el otorgamiento de contratos sobre parcelas que ya se encuentran otorgadas mediante contrato a otras personas naturales o jurídicas, así como por el incumplimiento de las cláusulas del contrato.

Arto. 78 Los usuarios que en la actualidad ocupen terrenos dentro de las tierras de los Pueblos o Comunidades Indígenas, en virtud de contratos celebrados con anterioridad a la entrada en vigencia de la presente Ley, seguirán usándolas y al vencimiento de los contratos se procederá con arreglo a las estipulaciones de la presente Ley.

\section{CAPITULO XI}

\section{EL DESARROLLO SOSTENIBLE EN EL TERRITORIO INDÍGENA}

Arto. 79 El concepto de desarrollo sostenible en los territorios indígena incluye como elementos fundamentales:

a) El reconocimiento y respeto absoluto por parte del Estado, de las formas de organización de los Pueblos y Comunidades Indígenas, la representación social y la administración de los territorios indígenas, conformes sus propias tradiciones e interés.

b) La capacidad de los Pueblos y Comunidades Indígenas para definir su propio desarrollo de conformidad con los derechos reconocidos en la Constitución Política de Nicaragua, en el Pacto Internacional de Derechos Económicos, Sociales y Culturales de las Naciones Unidas y demás instrumentos internacionales de protección a los derechos humanos de los Pueblos Indígenas.

c) La garantía de parte del Estado de implementar medidas particulares, de común acuerdo con la Autoridad Indígena, para proteger los territorios indígenas, recursos naturales, patrimonio arqueológico y cultural, y mejorar la infraestructura y condiciones de vida de los miembros de los Pueblos Indígenas. 
d) El respeto a la reivindicación de las costumbres y valores culturales propios, así como las normas consuetudinarias que regulan la convivencia social.

e) La seguridad jurídica y la estabilidad social en los territorios indígenas, a lo cual deben avocarse tanto las autoridades estatales como las indígenas, a fin de generar confianza a la inversión social y al desarrollo socio-económico, garantizando la conservación y restauración de los recursos naturales.

f) La responsabilidad de la Autoridad Indígena de atender la situación social de los miembros de los Pueblos y Comunidades Indígenas, administrando el patrimonio indígena en beneficio de estos Pueblos y Comunidades; y en correspondencia con esta responsabilidad deberán destinar al menos el cincuenta por ciento de sus ingresos en atención social, como: producción, salud, educación, alimentación, vivienda, cultura, y otras necesidades sociales, así como el desarrollo de proyectos de auto sostenibilidad para los Pueblos y Comunidades Indígenas.

Arto. 80 La Autoridad Indígena aprobará su Plan de Ordenamiento Territorial, dentro del territorio indígena, el que por lo menos deberá definir lo siguiente:
a) Áreas para conservación de recursos naturales.
b) Áreas para rescate de los recursos naturales renovables.
c) Áreas para utilización productiva, clasificando por tipo de cultivo.
d) Áreas de conservación cultural, arqueológicas y sitios sagrados.
e) Áreas para asentamientos humanos.
f) Áreas de otorgamiento eventual de concesiones de aprovechamiento de recursos renovables y no renovables.

Arto. 81 Para el impulso de estrategias del desarrollo sostenible, el Estado a través de las instituciones correspondientes, en coordinación con la Autoridad Indígena deberá elaborar, a más tardar dos años después de vigencia de la presente ley, un Diagnóstico sobre la situación de los Recursos Naturales y Patrimonio Arqueológico y Cultural de los Pueblos Indígenas, el cual servirá de base para la elaboración de una estrategia de restauración, conservación, utilización y desarrollo sostenible de tales recursos.

Arto. 82 Toda institución, en la creación de sus planes, programas o proyectos, y políticas; nacional o internacional, con fines o sin fines de lucro; antes de implementar acciones que involucren o afecten a los Pueblos o Comunidades Indígenas, deberá tener el consentimiento de la Autoridad Indígena.

El Estado no podrá autorizar ninguna concesión de exploración o explotación de recursos naturales como el agua, subsuelo, o turísticas, en territorio indígena o en áreas que puedan tener un impacto sociocultural, económico o ambiental sobre éstas, sin el previo, libre e informado consentimiento de los Pueblos y Comunidades Indígenas.

Para efectos de realizar la consulta, la entidad interesada entregará al Gobierno Indígena la documentación referida a la solicitud, los estudios de impacto ambiental, y otros documentos relacionados, con por lo menos, un mes de anticipación a la fecha de licitación.

Los Pueblos y Comunidades Indígenas deberán participar en los beneficios que reporten tales concesiones, programas y proyectos, y percibir una indemnización equitativa por cualquier daño que puedan sufrir como resultado de esas actividades.

Arto. 83 Para declarar áreas protegidas en tierras comunales, el Estado deberá acordar con el Gobierno Indígena la pertinencia o no de tal declaración, y la emisión del Decreto Legislativo correspondiente para emitir tal declaración. Previo consentimiento del Pueblo o Comunidad Indígena sobre cuyas tierras se pretende decretar el área protegida.

Arto. 84 Los Pueblos Indígenas podrán declarar áreas protegidas los sitios de sus territorios de acuerdo a cualquiera de las siguientes consideraciones: 
a) Áreas donde se encuentren especies vegetales y animales en peligro de Extinción;

b) Áreas deforestadas para la recuperación del recurso forestal;

c) Áreas de cuencas hidrográficas;

d) Áreas donde se encuentren objetos de importancia cultural o Arqueológicas;

e) Áreas de interés comunitario según definición de la Autoridad Indígena;

f) Áreas de belleza escénica; y

g) Por otras causas de interés social para el Pueblo o Comunidad Indígena.

Una vez declaradas estas áreas protegidas, la institución del Estado competente, deberá respetar y apoyar a la Autoridad Indígena en la implementación de las medidas y actividades de protección decretadas.

Arto. 85 La administración de áreas protegidas en tierras comunitarias, cuando haya sido declarada por el Estado, estará bajo la autoridad de los Pueblos o Comunidades Indígenas y el Estado. Para ello, los Pueblos o Comunidades Indígenas podrán auxiliarse de las organizaciones no gubernamentales ambientales que elijan, sin perjuicio del apoyo técnico que deberá brindarles la institución estatal correspondiente.

Arto. 86 El Plan de Manejo de las áreas protegidas en tierras comunales indígenas, se hará en conjunto con la Autoridades Indígena y la institución de gobierno correspondiente, para lo cual se tomará en cuenta las formas de uso tradicional de los recursos naturales que aplican los Pueblos Indígenas.

Arto. 87 Los Pueblos Indígenas del Pacífico, Centro y Norte de Nicaragua, tienen derecho a administrar, conservar y aprovechar de manera sostenible el bosque, la biodiversidad, el suelo, el agua, y demás recursos naturales existente en su territorio.

Las autoridades gubernamentales no permitirán la extracción ni la circulación de madera, piedra, arena, o cualquier otro recurso natural, proveniente de tierras o territorios indígenas sin que se le presente el correspondiente permiso, de la Autoridad Indígena.
De los montos que el Estado percibe en concepto de ingreso por:

concesiones, aprovechamiento, multas, derecho de vigencia, subastas por decomisos, conforme a la ley No. 462, Ley de Conservación, fomento y desarrollo sostenible del sector forestal deberá enterarse el veinticinco por ciento al Pueblo o Comunidad Indígena en cuyo territorio se encuentre el recurso a aprovecharse.

De la misma manera, se aplicará esta disposición a las recaudaciones provenientes de las concesiones sobre pesca, minería, petróleo y agua, otorgados en territorios indígenas.

Arto. 88 Todos los Pueblos y Comunidades Indígenas del Pacifico, Centro y Norte de Nicaragua que tengan tierras en las costas del mar, lagos y lagunas, tendrán derecho a percibir un veinticinco porciento de los ingresos provenientes de las concesiones por el uso de las playas. Estas concesiones deberán respetar el derecho al uso de caminos tradicionales para el acceso de los Pueblos y Comunidades Indígenas.

\section{CAPITULO XII}

\section{DISPOSICIONES FINALES Y TRANSITORIAS}

Arto. 89 A partir de la entrada en vigencia de la presente ley, las autoridades de cada Pueblo o Comunidad Indígena podrán publicar gratuitamente sus Estatutos y Reglamentos Internos con los ajustes que correspondan a la presente Ley, en La Gaceta, Diario Oficial, para su debida publicación y entrada en vigencia.

Arto. 90 Los ciudadanos no indígenas que al momento de entrada en vigencia de la presente Ley detenten tierras indígenas en cualquier carácter, deberán acudir ante el Gobierno Indígena correspondiente, para actualizar su situación legal, de conformidad con lo establecido por la presente Ley.

Arto. 91 Las Junta Directivas, Consejos de Ancianos, 
Monexicos, Reformas, Alcalde de Vara, u otras denominaciones de la Autoridad Indígena, que al momento de la publicación de la presente ley hayan sido elegidas, seguirán en el ejercicio de sus cargos por el período en que fueron electas, de conformidad con sus Estatutos, usos y costumbres.

Arto. $92 \mathrm{La}$ presente ley es de orden público, por su naturaleza es de carácter social y por razón de la materia es de carácter especial.

Arto. 93 A partir de la fecha de entrada en vigencia de la presente ley, queda expresamente prohibida la expedición de Títulos Supletorios, Títulos de Reforma Agraria, y cualquier otro título de procedencia judicial, sobre tierras tradicionales o tituladas a favor de los Pueblos y Comunidades Indígenas regulados por la presente Ley.

Arto. $94 \mathrm{La}$ presente Ley cancela de mero derecho las inscripciones de los Pueblos y Comunidades Indígenas que estén inscrito actualmente en el Departamento de Registro y Control de Asociaciones del Ministerio de Gobernación amparados en la Ley 147.

Arto. 95 Esta ley deroga el Decreto Legislativo del 27 de Diciembre de 1902, publicado en La Gaceta, Diario Oficial, numero 1856 del 22 de Enero de 1903. Ley del 16 de Febrero de 1906, publicada en La Gaceta, Diario Oficial, número 2745 del 21 de Febrero de
1906, Decreto Ejecutivo del 20 de Febrero de 1908, publicado en la Gaceta, Diario Oficial, número 25 del 27 de Febrero de 1908. Ley del 3 de Junio de 1914, publicado en La Gaceta, Diario Oficial, numero 128, del 6 de Junio de 1914, Decreto Ejecutivo del 6 de Agosto de 1918, publicado en La Gaceta, Diario Oficial, numero 182 del 14 de Agosto de 1918. El Decreto Ejecutivo del 26 de Noviembre de 1943, publicado en La Gaceta, Diario Oficial, numero 258 del 1ro. de Diciembre de 1943. Decreto Ejecutivo número 491 del 10 de Marzo de 1952, publicado en La Gaceta, Diario Oficial, numero 57 del 11 de Marzo de 1952. Los Acuerdos Presidenciales número 902 del 29 de Marzo de 1968 y el número 167 del 10 de Abril de 1970 publicados en La Gaceta, Diario Oficial, número 81 del 15 de Abril de 1970 y cualquier otra disposición administrativa o ley que se le oponga.

Arto. 96 La presente Ley entrara en vigencia a partir de su publicación por cualquier medio de comunicación social escrito, sin perjuicio de su posterior publicación en La Gaceta, Diario Oficial.

Dado en la ciudad de Managua, en la sala de sesiones de la Asamblea Nacional, a $\operatorname{los}$ días del mes de del año Dos mil , Presidente de la Asamblea

Nacional, , Secretario de la 